\title{
Application of Volterra functions to X-31 aircraft model motion
}

\author{
Adam Jirásek*and Russell M. Cummings ${ }^{\dagger}$ \\ United States Air Force Academy, USAFA, CO 80840, USA
}

\begin{abstract}
Recent advances towards an efficient computational method for accurately determining the stability and control characteristics of an aircraft are discussed and critiqued. The present approach with greatest promise is to reduce the number of high-fidelity CFD simulations by using Volterra functions Reduced Order Modeling. This type of reduced order model is a predictive model which has a unique training maneuver - a unit impulse. The advantage of such an approach is the fast prediction of the aerodynamic characteristics of an aircraft. This article presents the results of application of the Volterra functions ROM for prediction of linear movement of a 2D airfoil and of an X-31 aircraft model. The Volterra ROM predicted well normal and axial force which are linear or weakly non-linear and was in a fairly good agreement with pitching moment as long as the pitching moment predictions were weakly non-linear.
\end{abstract}

\section{Nomenclature}
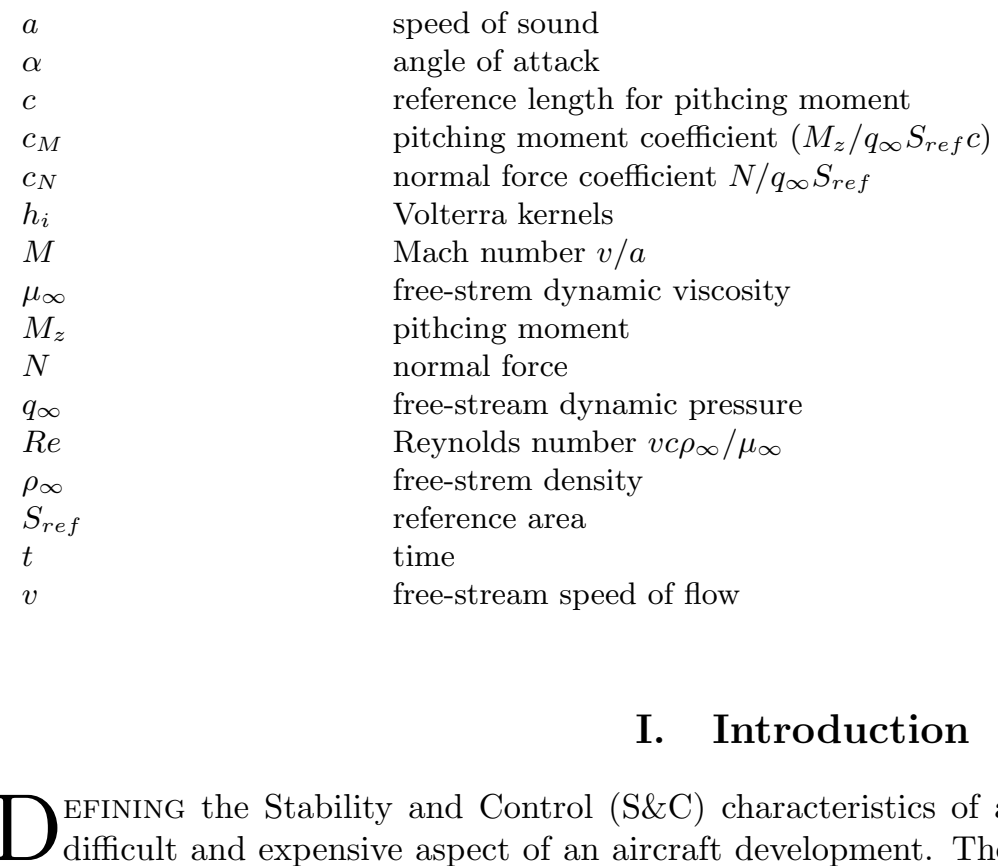

\section{Introduction}

$\mathrm{D}$ EFINING the Stability and Control (S\&C) characteristics of an airplane is probably one of the most difficult and expensive aspect of an aircraft development. The difficulties are partially due to the fact that the S\&C phase of design is extended to the very end of the development process, and sometimes even beyond it, causing occasionally unexpected and expensive twists along the project paths requiring changes on the aircraft. Some recent examples include aircraft such as F/A-18 and F-18 HARV or F-22. ${ }^{1-6}$ Since these can occur in the very late stages of the project, they are very expensive and often comes with detrimental effect to the expected performance. It is therefore of utmost importance to be able to predict $\mathrm{S} \& \mathrm{C}$ characteristics of the aircraft in the early stages of its development.

*National Research Council, NRC, Research Associate, Department of Aeronautics, AIAA Senior Member

${ }^{\dagger}$ Professor of Aeronautics, Department of Aeronautics, AIAA Associate Fellow 
Several tools can be used to predict the S\&C characteristics of an aircraft. The first class of methods work in a real physical space - flight testing and wind tunnel testing. Flight testing is the most accurate method since it involves accurate modeling of all physical phenomena. But is also the most expensive and cannot be used during early stages of the aircraft development process, simply because the aircraft configuration may not exist. Wind tunnel testing is also accurate, however usually works in different limits of the physical space - i.e. different Reynolds number, different Strouhal number, smaller dimensions of the physical space biased by uncertainties in boundary conditions, etc. In addition, wind tunnel testing is also expensive, though cheaper than flight testing. The second class of methods works with models of a different level of fidelity for a real physical space. It is cheaper than the first class, however, comes with questions about validity and reliability. Although not always the case, the higher the fidelity of a method, the increased reliability and longer execution time which can be expected. One of the high fidelity modeling tools recently used to study the non-linear behavior of an aircraft is Computational Fluid Dynamics (CFD). This high fidelity method reduces some of the major uncertainties connected to modeling of the real physical space, however, this improvement comes with an additional cost in execution time. One of the major causes of this is computer performance combined with a usually very short physical time step required to accurately capture the flow physics. This is exaggerated by the low frequency nature of most of the motions of interest requiring modeling of long time sequences. Researchers at NASA Ames, for example, have attempted to perform a "brute force" approach to filling a stability and control database for vehicle design. ${ }^{7-9}$ They found that a reasonable database for static stability and control derivatives would include on the order of 30 different angles-of-attack, 20 different Mach numbers, and 5 different side-slip angles, each for a number of different geometry configurations or control surface deflections. ${ }^{7}$ They envisioned that a few hundred solutions can be obtained automatically and the remainder of the parameter space filled out with the use of an interpolation procedure or neural networks. Considering today's performance of computers and CFD codes, the routine calculations of hundreds of maneuvers in a reasonable time frame is unrealistic. In order to accurately and reliably predict the stability and control $(\mathrm{S} \& \mathrm{C})$ characteristics of an aircraft prior to the costly flight test phase, CFD has to be combined with a predictive modeling of lower complexity. Several types of Low Order Modeling is currently under investigation at USAFA. One of them is based on generation of a nonlinear, dynamic reduced-order aerodynamic model using least the square approximation. Such method uses CFD to model an appropriate flight maneuvers and then, using a code called SIDPACK build a low order non-linear model which then can be used to predict similar mmaneuvers. ${ }^{10-12}$ Another of the lower-order methods which can be effectively used in combination with CFD is Volterra functions reduced order modeling. It has been successfully used for aeroelastic studies of the limit cycle oscillations. ${ }^{13-16}$ This article presents a study

of application of the Volterra theory into the area of stability and control. At this stage the application is limited to cases which are linear or close to linear. Investigated motions are pitching motions.

\section{Volterra Theory}

The Volterra theory is an extension of the Taylor series expansion in time. It is defined by the equation

$$
\begin{aligned}
y(t)=h_{0}+\int_{0}^{t} h_{1}(t-\tau) u(\tau) d \tau & +\int_{0}^{t} \int_{0}^{t} h_{2}\left(t-\tau_{1}, t-\tau_{2}\right) u\left(\tau_{1}\right) u\left(\tau_{2}\right) d \tau_{1} d \tau_{2}+ \\
& +\sum_{n=3}^{N} \int_{0}^{t} \ldots \int_{0}^{t} h_{n}\left(t-\tau_{1}, \ldots . ., t-\tau_{N}\right) \Pi_{n=3}^{N} u\left(\tau_{n}\right) d \tau_{N}
\end{aligned}
$$

where $y(t)$ is an output, $u(t)$ is an input and $h_{1}, h_{2}, . . h_{n}$ are Volterra kernels. The Volterra series has been extensively used in electrical engineering, signal processing, image processing and biology and medicine, however, its use in aerodynamics is rare and rather new. One of the first who formally introduced the Volterra functions into CFD was Silva in his dissertation. ${ }^{17}$ His first step was the truncation of the third and higher terms of the Volterra functions. The discretization of the second order Volterra series for a discrete time step $\Delta t$ is

$$
y(n)=h_{0}+\sum_{k=0}^{N} h_{1}(n-k) u(k)+\sum_{k_{1}=0}^{N} \sum_{k_{2}=0}^{N} h_{2}\left(n-k_{1}, n-k_{2}\right) u\left(k_{1}\right) u\left(k_{2}\right)
$$

Once the kernels are known, the equation (2) predicts an output of the weakly non-linear system to the input at any frequency. The kernels are found according to Silva. ${ }^{17}$ The linear kernel is a combination of 
the response to unit and double unit impulses at time $t_{1}=T$. The second-order kernel is a combination of two successive unit impulses at time $t_{1}=T$ and $t_{2}=T+\Delta T$ and two unit pulses, one at time $T$, second at time $T+\Delta T$

$$
\begin{aligned}
h_{1}(t) & =2 w_{1}\left(t_{1}\right)-\frac{1}{2} w_{2}\left(t_{1}\right) \\
h_{2}\left(t_{1}, t_{2}\right) & =\frac{1}{2}\left(w_{1}\left(t_{1}, t_{2}\right)-w_{1}\left(t_{1}\right)-w_{1}\left(t_{2}\right)\right)
\end{aligned}
$$

The algorithm is shown in Figure 1 for both the first and the second order kernel. The Volterra theory has

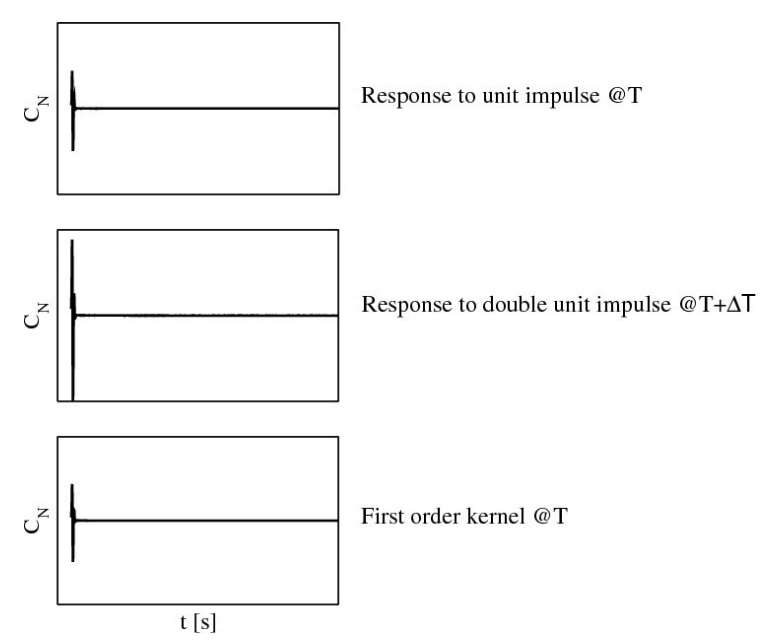

(a) Kernel $h_{1}$ - see equation (3)
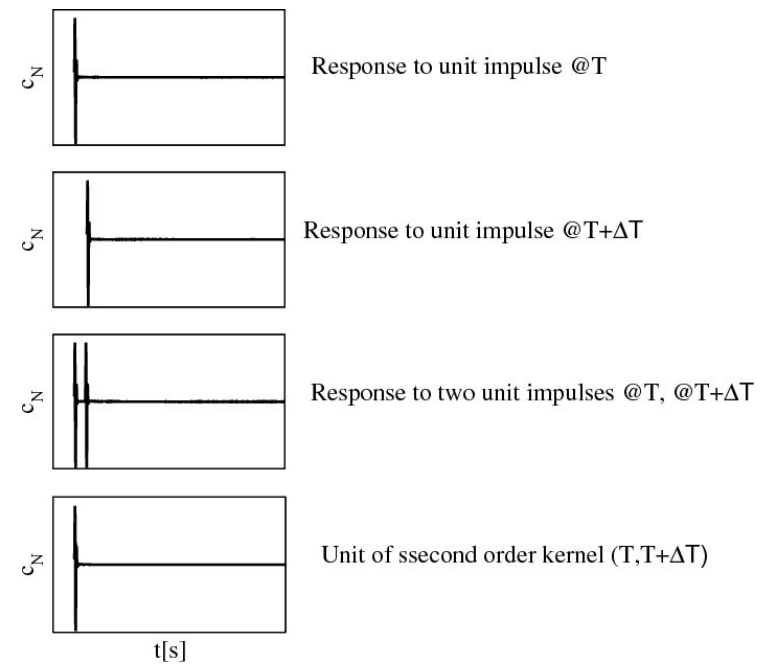

(b) Kernel $h_{2}$ - see equation (4)

Figure 1. First and second order kernels

been successfully used in aeroelasticity ${ }^{13-16}$ to predict limit cycle oscillations. The aim of this work is to extend the use of the Volterra theory to the area of Stability and Control. The work presented in this article present the application of the Volterra theory in cases of linear motion.

\section{Cobalt CFD code}

Cobalt $^{18}$ is a cell-centered, finite volume CFD code. It solves the unsteady, three-dimensional, compressible Reynolds Averaged Navier-Stokes $(R A N S)$ equations on hybrid unstructured grids. Its foundation is based on Godunov's first-order accurate, exact Riemann solver. Second-order spatial accuracy is obtained through a Least Squares Reconstruction. A Newton sub-iteration method is used in the solution of the system of equations to improve time accuracy of the point-implicit method. Strang et al. ${ }^{18}$ validated the numerical method on a number of problems, including the Spalart-Allmaras model, which forms the core for the Detached Eddy Simulation $(D E S)$ model available in Cobalt. Tomaro et al. ${ }^{19}$ converted the code from explicit to implicit, enabling CFL numbers as high as $C F L \approx 10^{6}$. Grismer et al. ${ }^{20}$ parallelized the code, with a demonstrated linear speed-up on as many as 4,000 processors. The parallel METIS (PARMETIS) domain decomposition library of Karypis et al. ${ }^{21}$ is also incorporated into Cobalt. New capabilities include rigid-body and 6 DOF motion, equilibrium air physics. An overset grid capability and a coupled aeroelastic simulation capability is also implemented. The code has been extensively used for S\&C analysis of a number of aircraft. ${ }^{10,12,22-25}$

\section{2D Airfoil Test}

Figure 2 shows the first order kernel of normal force of a NACA0012 airfoil. The kernel was extracted from the unit and double unit pulse response using equation (2). The pitch motion is realized by rotating the entire mesh around the quarter chord point. The unit signal corresponds to a pulse in pitch of $2 d e g$. 


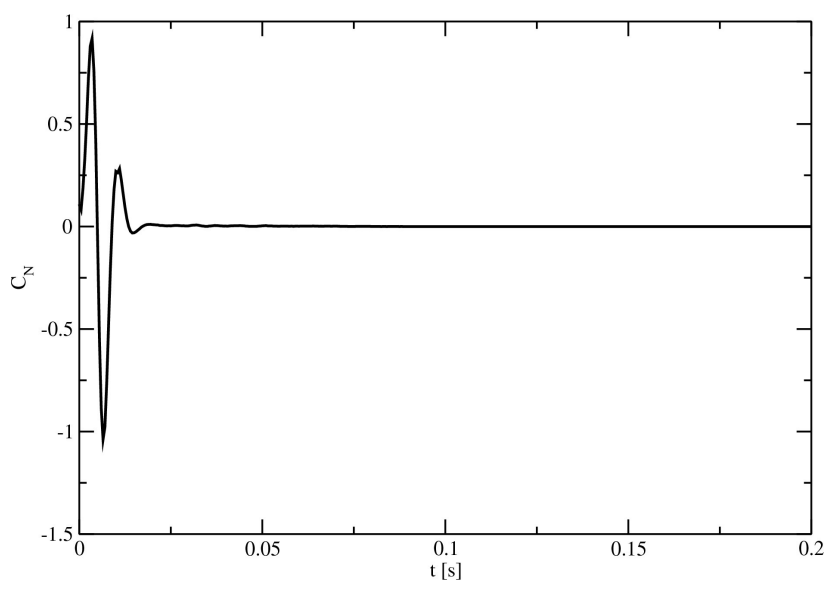

Figure 2. Linear kernel

Comparing the linear kernel to the response to a unit pulse shows almost identical curves, suggesting the system is linear. Figure 3 shows the comparisons of linear convolution to the full CFD solutions for simple sinusoidal motions at three different frequencies, 5,10 and $20 \mathrm{~Hz}$ two sinusoidal motions with two different

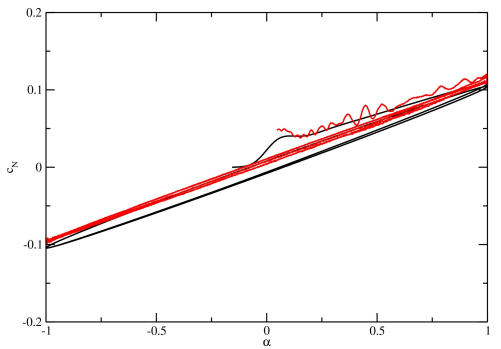

(a) $5 \mathrm{~Hz}$

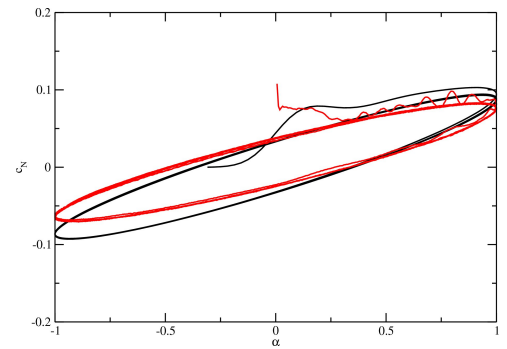

(b) $10 \mathrm{~Hz}$

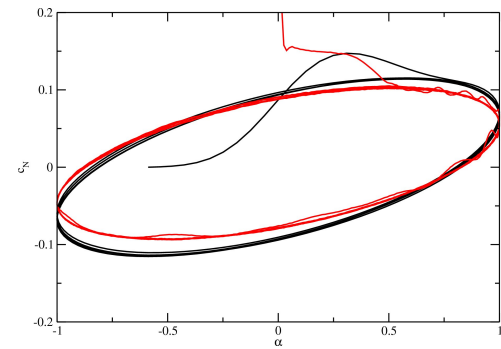

(c) $20 \mathrm{~Hz}$

Figure 3. NACA0012 airfoil, inviscid flow - sinusoidal motion, black - ROM model, red - CFD

frequencies and amplitudes.

The next set of figures (Figs 4) show the comparisons of the viscous flow solution with a linear convolution for a sinusoidal motion at three frequencies. The motion of the airfoil was realized by using a mesh around the airfoil which is moving on the stationary primary mesh. Of interest is that initial clockwise direction at

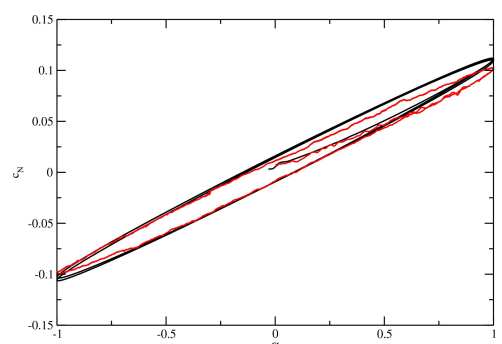

(a) $5 \mathrm{~Hz}$

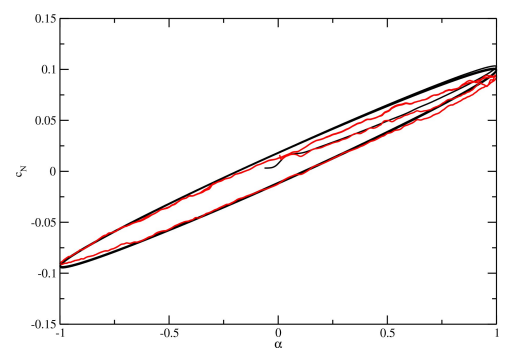

(b) $\mathbf{1 0 H z}$

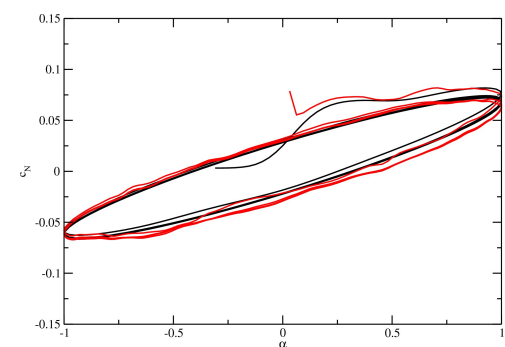

(c) $50 \mathrm{~Hz}$

Figure 4. NACA0012 airfoil, viscous flow - sinusoidal motion, black - Volterra ROM model, red - CFD

lower frequencies changes to counterclockwise motion at a frequency of $50 \mathrm{~Hz}$, the trend which is correctly reproduced by Volterra ROM. The last figure 5 shows the comparison motion defined by two sinusoidal motions at two frequencies and amplitudes, $\alpha=A_{1} \sin \left(\omega_{1} t\right)+A_{2} \sin \left(\omega_{2} t\right)$. These airfoil results shows that the Volterra/ROM is capable of modeling motion for any time dependent angle of attack. 


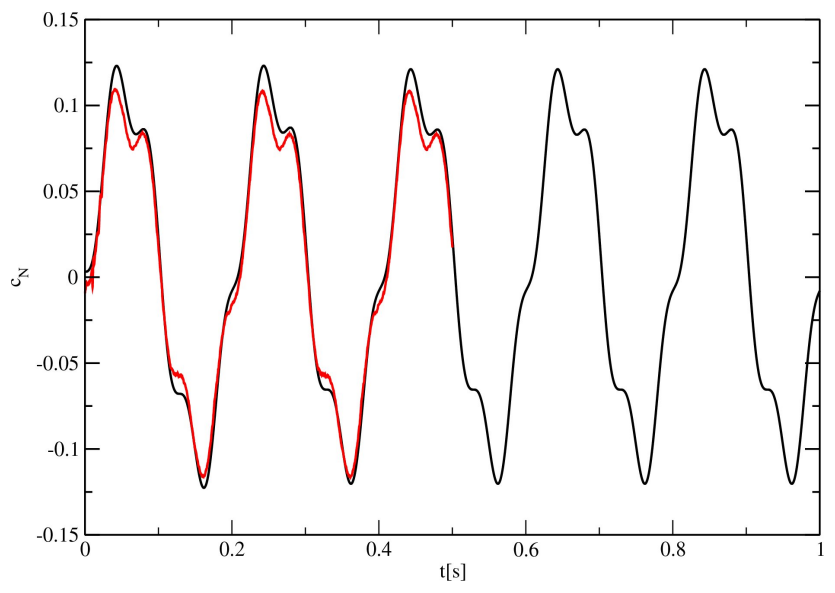

Figure 5. NACA0012 airfoil, inviscid flow - double sinusoidal motion, black - Volterra ROM, red CFD solution

\section{X-31 aircraft model}

The X-31 $26-28$ is a typical case of an advanced fighter aircraft. It has been a subject of numerous flight tests ${ }^{29-33}$ wind tunnel tests ${ }^{34,35}$ and CFD. ${ }^{36,37}$ This test case has been provided to the partners participating in NATO RTO task group AVT-161 (Assessment of Stability and Control Prediction Methods for NATO Air and Sea Vehicles). The objective of this task group is to evaluate CFD codes against wind tunnel data sets of two different aircraft configurations. A wind tunnel model used in experiments at DLR contains the canard, the LEX, the wind, the fuselage flap, the horizontal stabilizator and the rudder. ${ }^{35}$ The test setup does not consider any flow through the inlet. The wind tunnel model was equipped with the moving lift and control surfaces. Between each of the surface and the main body of the model were enabling mechanical movement of the surface. The effect of the gaps has been investigated in the wind tunnel ${ }^{35}$ and using CFD. ${ }^{37}$ It has been found that gaps substantially alter the flow-field above the wing giving rise to two co-rotating primary vortices. ${ }^{37}$ The values of the global lift, drag and momentum coefficients were, however, changed only mildly. Considering this mild dependence of the global forces/moments and in order to avoid having prohibitively large meshes used for unsteady CFD tests, the gaps in the model were sealed. The model is mounted in the wind tunnel using two setups. The first setup uses a belly mounted sting connecting the model to the support desk in the wind tunnel ceiling. The sting - model fuselage junction is located right under the main wing. This setup enables six degrees of freedom motions. The second setup uses an aft mounted sting connected to an arm in the wind tunnel.

\section{A. Computational Meshes}

The mesh generation process consists of two steps. In the first step, the inviscid tetrahedral mesh is generated using IcemCFD code. This mesh is then used as a background mesh in the second step in the mesh generator TRITET. ${ }^{38,39}$ TRITET first builds prism layer using frontal technique and then rebuilds the inviscid mesh while respecting size of the original inviscid mesh from IcemCFD. The mesh has nominally 18 prism layers with the stretching ratio of 1.18. The total number of cells is 13 million. Figure 6 shows the unstructured mesh around the X-31 geometry. These cases are very sensitive to the leading edge resolution. The mesh around the leading edge was clustered as shown in Figure 7. The clustering process was controled by setting the maximum allowed deviation of the face of mesh cells from the surface of the aircraft.

The boundary conditions were farfield on the farfield boundary, symmetry on the symmetry plane and solid wall on the surface of the aircraft. All of the dynamic CFD simulations were performed at the Arctic Region Supercomputing Center (ARSC) on Midnight, a Sun cluster comprised of 2312 Opteron processors with a 68 TB Lustre file system. 


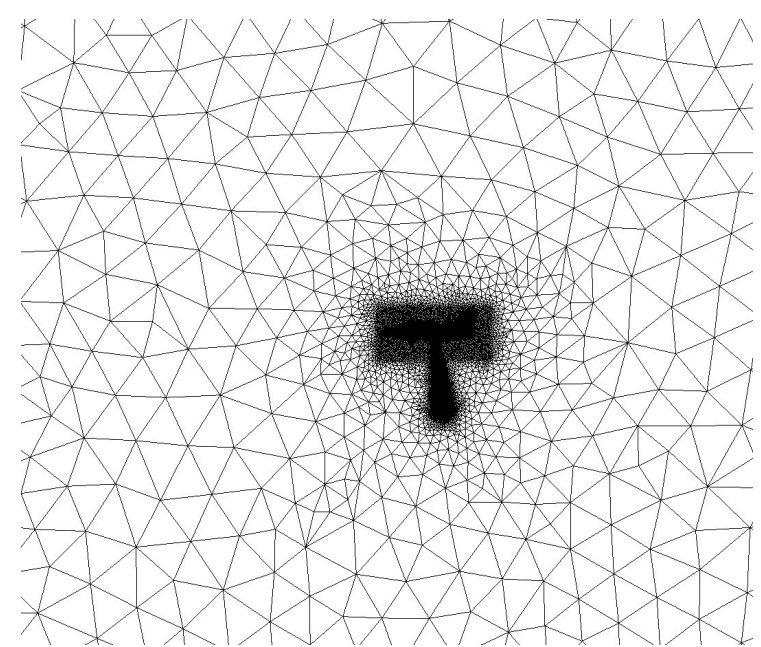

(a) Mesh in symmetry plane

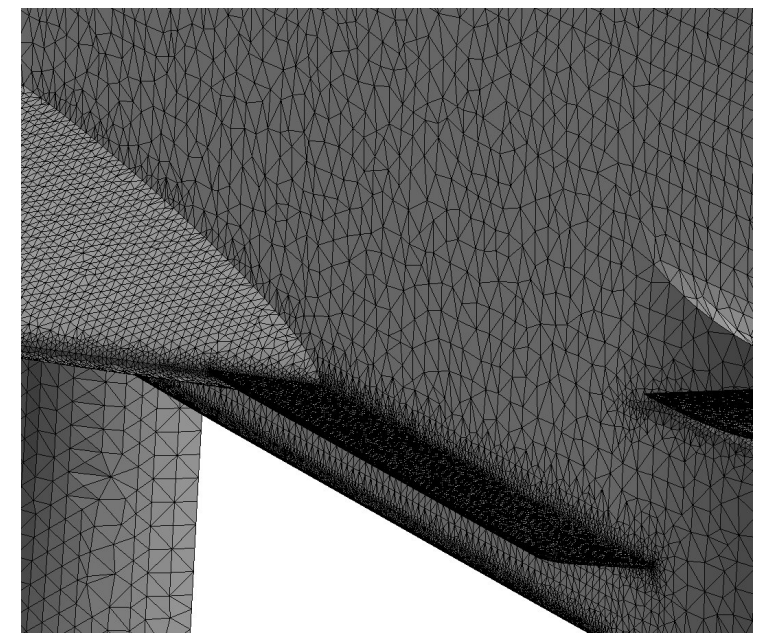

(c) Surface mesh around LEX

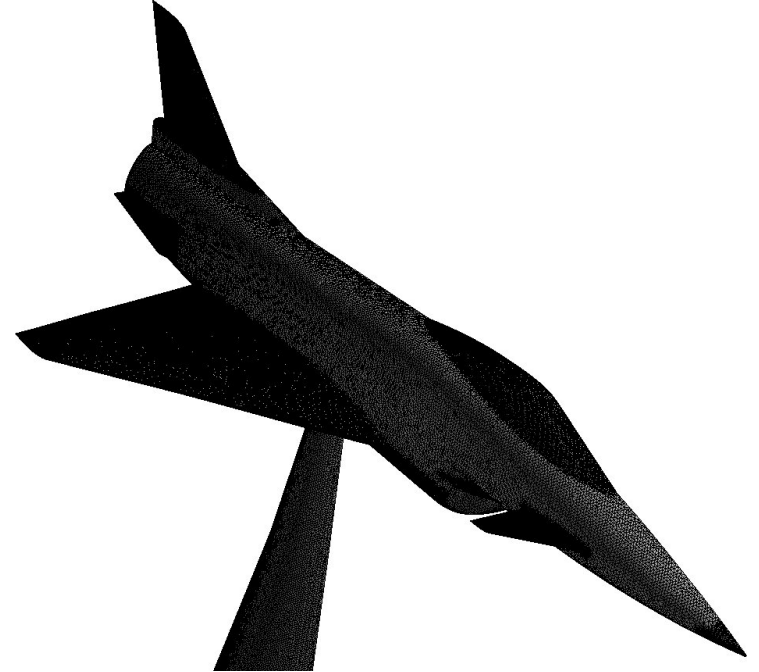

(b) Surface mesh around aircraft with belly mounted sting

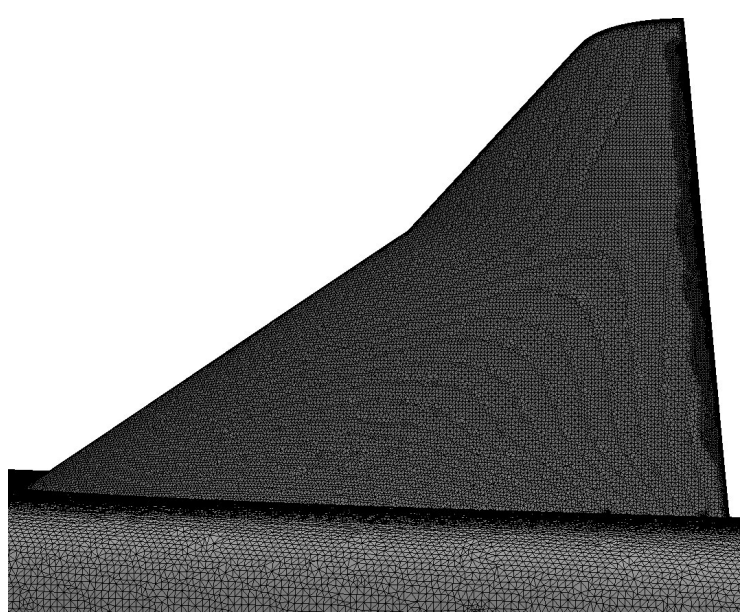

(d) Surface mesh on the wing

Figure 6. Mesh around X-31 aircraft model

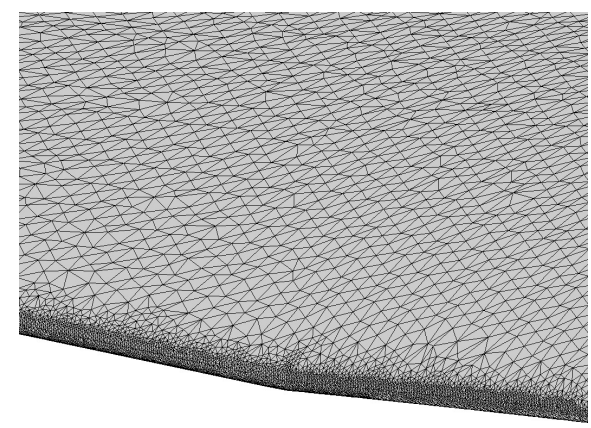

Figure 7. Mesh around wind leading edge with clustered cells, X-31 aircraft model 


\section{B. Steady Calculations}

The steady calculations were carried out at Mach number $M=0.18$, angle of attack $\alpha=20.06 \mathrm{deg}$ and Reynolds number $R e=2.07 \times 10^{6}$. The comparison of pitching moment shows difference between the SA turbulence model and SA model with rotational corrections (SARC). The SARC model brings a substantial

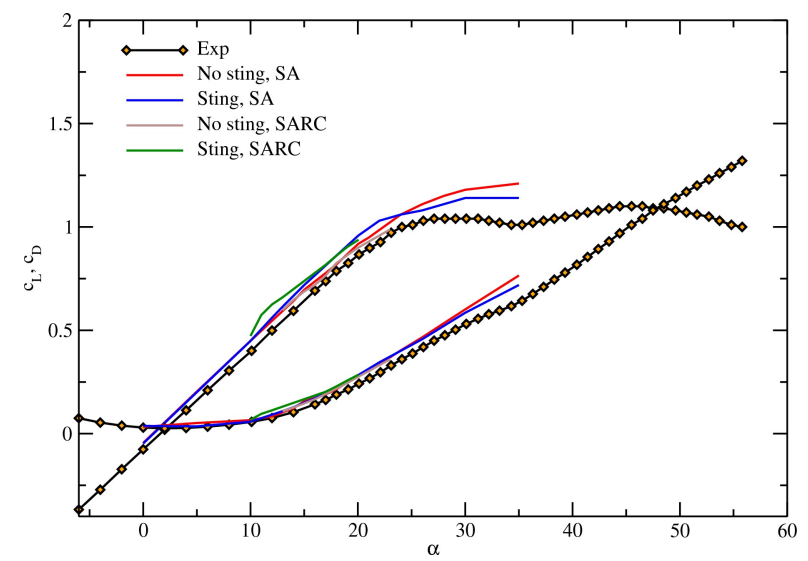

(a) $c_{L}, c_{D}$

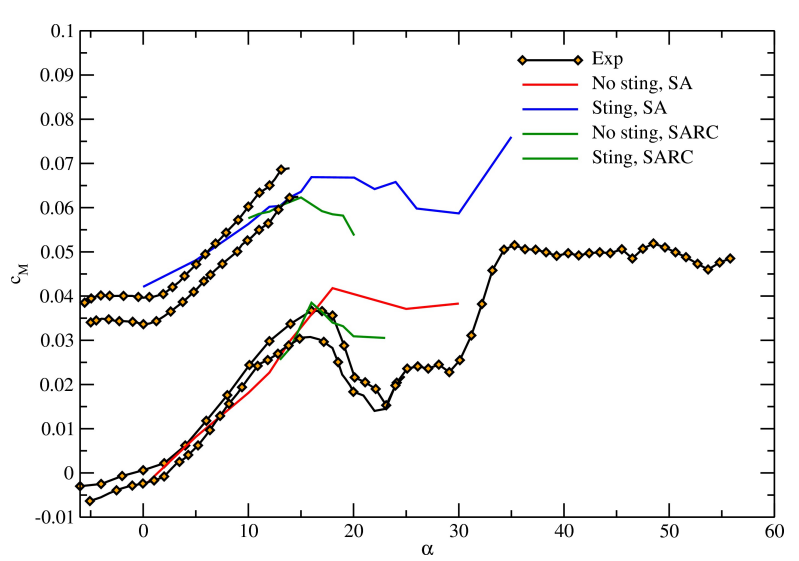

(b) $c_{M}$

Figure 8. Lift, drag and pitching moment, different turbulence models, X-31 model, Mach number $M=0.18$, Reynolds number $R e=2.07 \times 10^{6}$

improvement of the results. The results of SA model were not able to capture the abrupt change of character of the pitching moment curve at angle $15 \mathrm{deg}$. Instead it predicted linear growth of the pitching moment up to angle of attack 18deg followed by plateau and small, steady reduction in pitching moment. The SARC turbulence model predicts the abrupt change of the pitching moment curve at angle of $15 d e g$, however the drop in value of pitching moment was not as large as shown by the wind tunnel data.

\section{X-31 pitching motion}

The test with the X-31 was done in pitch for normal force and pitching moment. As summarized $\mathrm{in}^{40}$, the model is equipped with a belly mounted sting which strongly affects the pitching moment. It also can affect the noise in the solution. ${ }^{41}$ Meanwhile the average values of pitching moment can be corrected by subtracting the offset due to belly mounted sting, the noise in both normal force (see figure 9) and pitching moment caused by the sting has a detrimental effect on the assumption of fading memory. Unlike a model

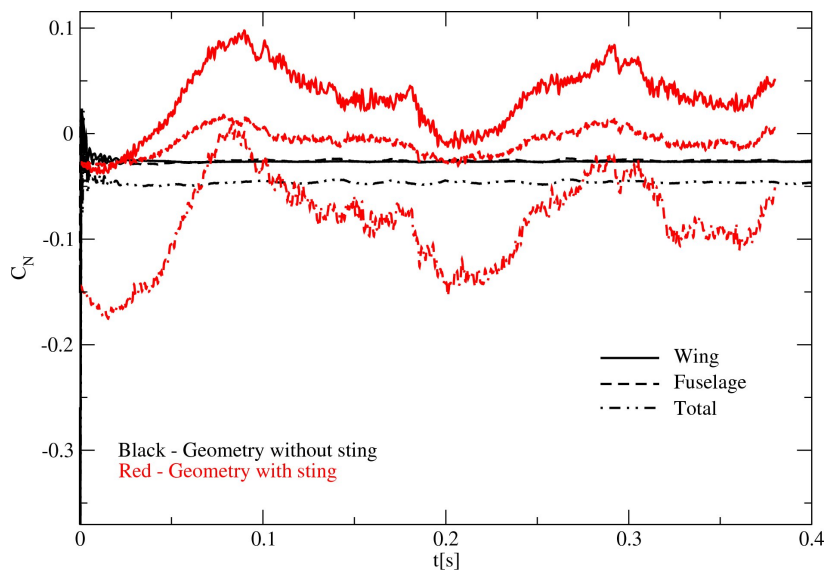

Figure 9. Normal force coefficient, geometry without and with belly mounted sting, X-31 model, Mach number $M=0.18$, angle of attack $\alpha=0 \mathrm{deg}$, Reynolds number $R e=2.07 \times 10^{6}$

with the sting, the model without the sting shows steady values of both normal force and pitching moment without any excessive noise. It is therefore the model without a sting which is used for this analysis. The 
kernels for the normal and axial force were calculated using SA model with an Gaussian shaped impulse with amplitude 15deg and are shown in Figure 10. The normal force is linear up to angle of $\alpha=25 \mathrm{deg}$ suggesting

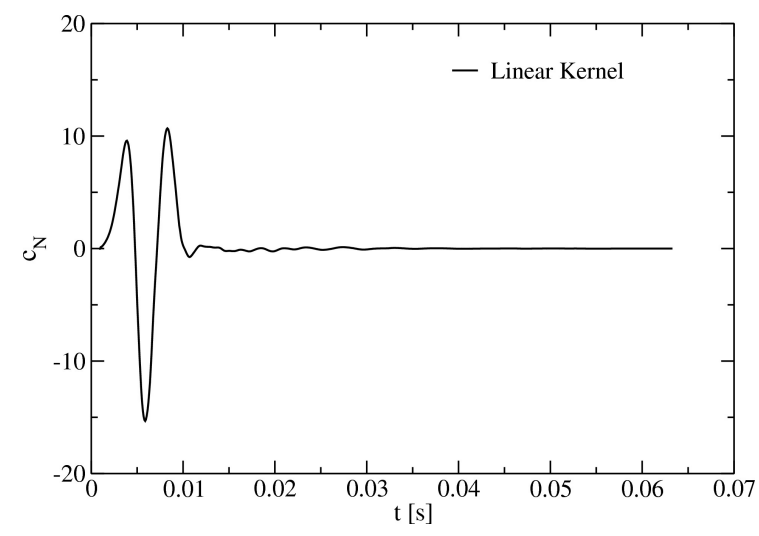

(a) Normal force

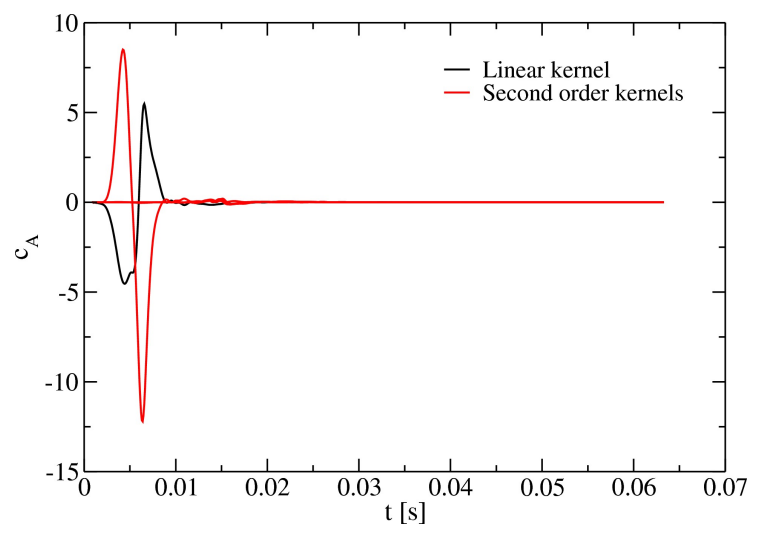

(b) Pitching moment

Figure 10. Linear kernels for normal force and pitching moment

only linear kernel will be used. The axial force shows non-linear behavior, the Volterra ROM used to model the axial force therefore includes first five terms of the second order also. Figure 11 shows the comparison of steady state normal force and axial force coefficient to the full CFD solutions.

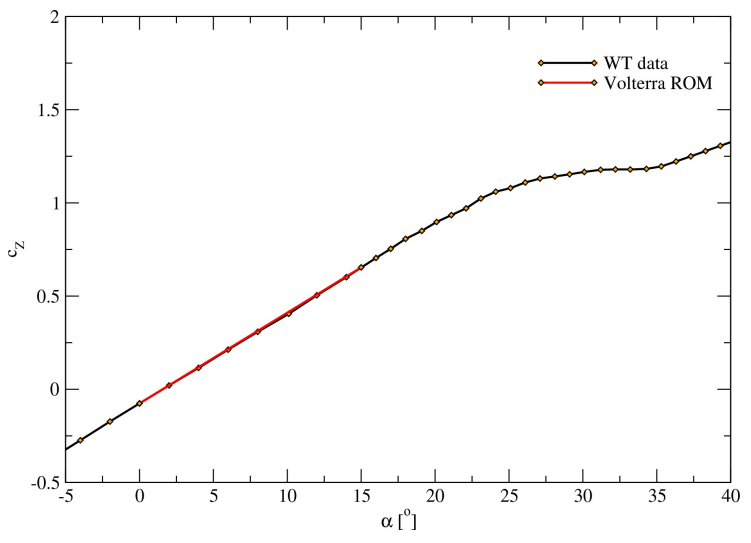

(a) Normal force coefficient

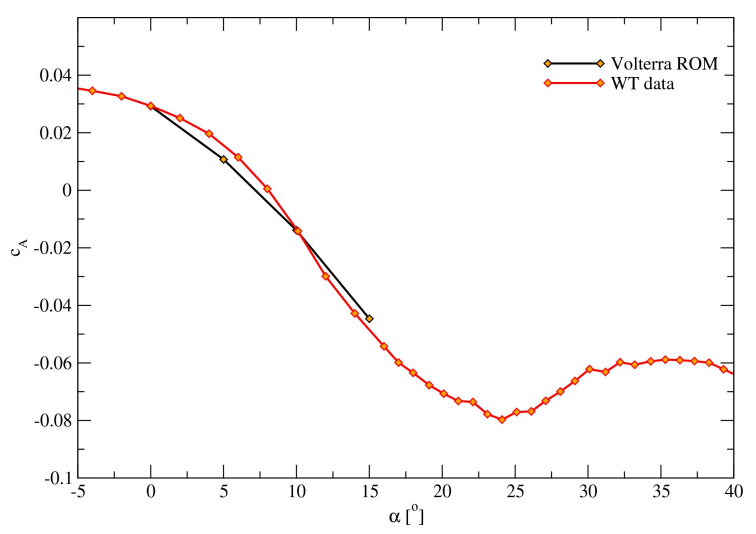

(b) Axial force coefficient

Figure 11. Prediction of static values of normal and axial force coefficient, X-31 model, Mach number $M=0.18$, Reynolds number $R e=2.07 \times 10^{6}$

Figure 8(b) shows strong non-linearity of the pitching moment curve after angle of attack $\alpha=15 \mathrm{deg}$. This non-linearity would be very difficult to model by the second order Volterra ROM with a sequence of unit pulses from the zeroth angle. The pitching moment is therefore modeled using a linear kernel with a $2 \mathrm{deg}$ pulse and its validity is limited to the linear dependency of pitching moment. The kernel for the pitching moment is shown in Figure 12

Figure 13 shows the pitching moment curve with wind tunnel and CFD data.

The Volterra ROM was applied to prediction of an X-31 pitching motion shown in Figure 14(a). Figures 14(b) and 14(c) shows dependency of normal and axial force coefficient. The comparison of the normal force with wind tunnel data is very good, the axial force data agrees reasonably well, in particularly considering amount of noise in wind tunnel data.

Figure 14(d) shows the comparison of pitching moment. Since the Volterra ROM was trained using the model without belly mounted sting, the moment curve was corrected by the constant offset caused by the sting - see Figure $8(\mathrm{~b})$. The figure shows differences between the Volterra ROM and the wind tunnel data at angles above $\alpha \approx 15 \mathrm{deg}$, which is a data sequence around $t=1 \mathrm{sec}$ and around $t=3 \mathrm{sec}$. The Volterra ROM predicts increase in pitching moment as the angle of attack increases, the wind tunnel data shows drop in 


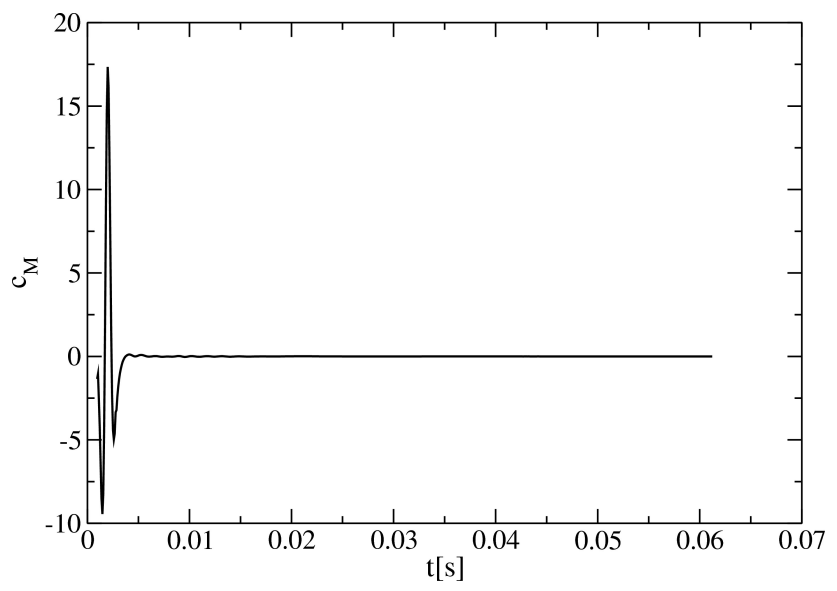

Figure 12. Linear kernel for pitching moment

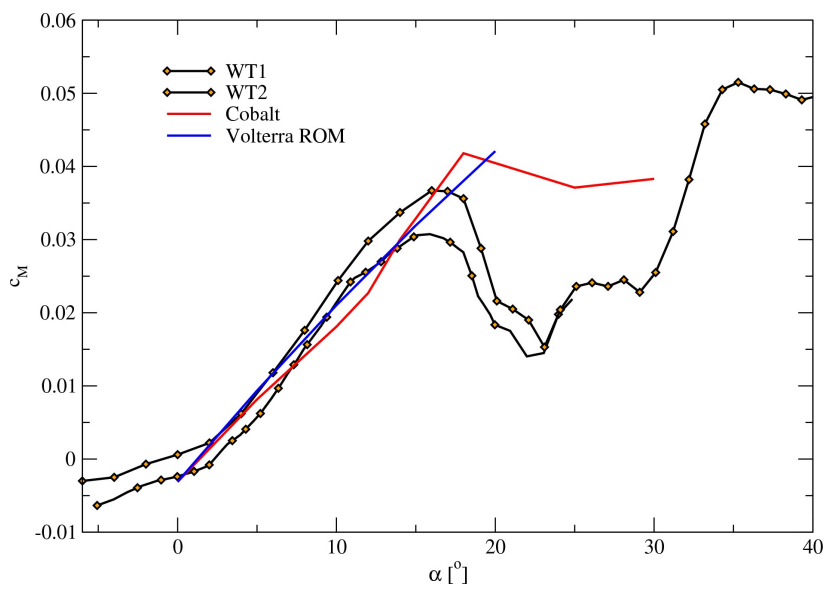

Figure 13. Pitching moment, X-31 model, Mach number $M=0.18$, Reynolds number $R e=2.07 \times 10^{6}$ 
the pitching moment above this angle. There is also a shift in time between Volterra ROM and wind tunnel data even at linear portion of the pitching moment which remains to be investigated.

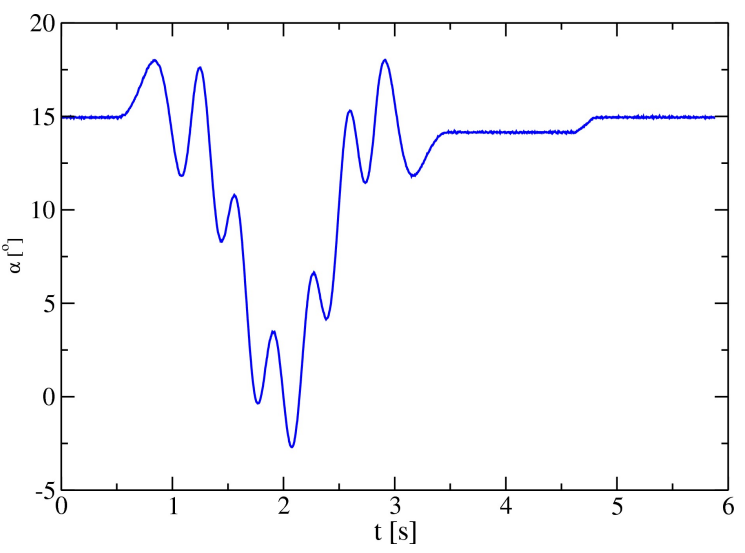

(a) Angle of attack

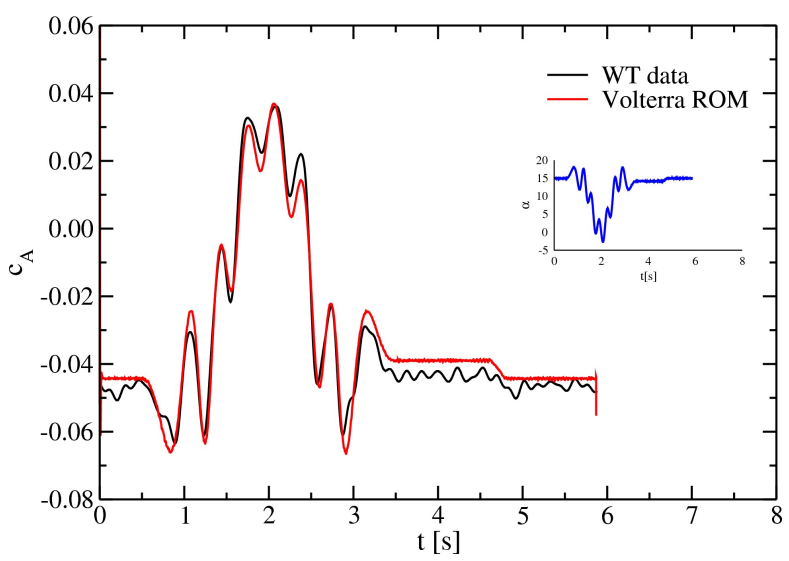

(c) $c_{A}$ coefficient

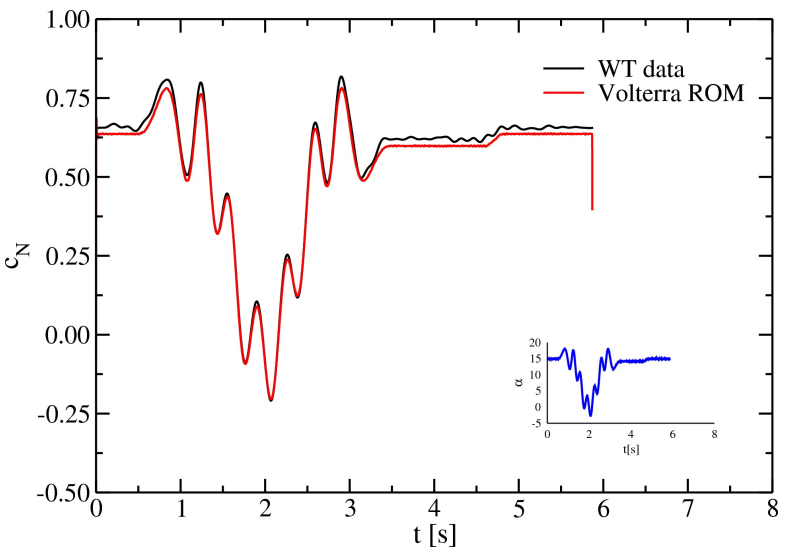

(b) $c_{N}$ coefficient

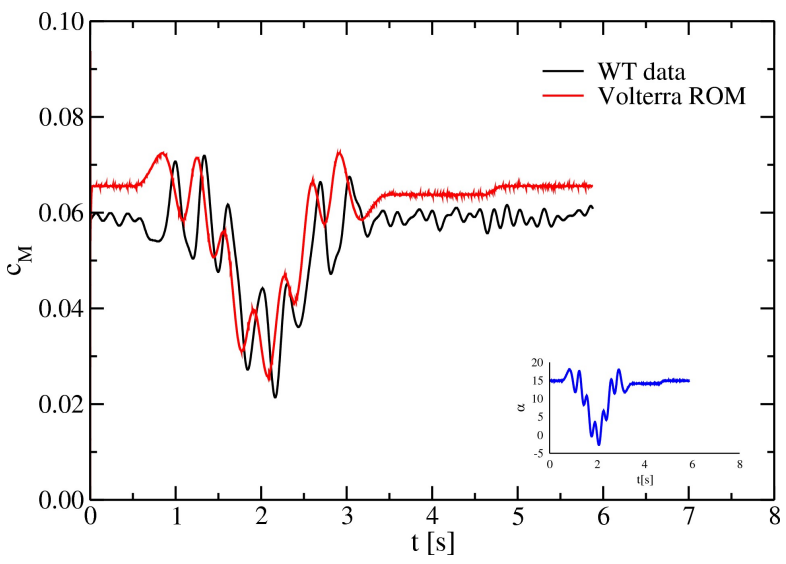

(d) $c_{M}$ coefficient

Figure 14. Normal force and axial force coefficient of prescribed motion, X-31 model, Mach number $M=0.18$, Reynolds number $R e=2.07 \times 10^{6}$

In summary, the Volterra ROM predictions are not always perfect, however they may be good enough to predict S\&C problems and regimes of necessary further investigations.

\section{Conclusion}

The article presents the application of the Volterra functions/ROM into the area of stability and control, for a linear motion. Both modeling of the normal force and the pitching moment were tried and compared to the CFD solution. The Volterra functions in this article are limited to cases which are linear. It has been shown that application of the Volterra theory into unsteady CFD modeling leads to great savings of time. For example, the X-31 test case which represents a typical problem where CPU time can be a prohibitive factor, the savings in the first step was around 25, due to necessity to obtain the Volterra kernels. Once the kernels are known, the Volterra/ROM can be used to quickly predict the time dependent values of normal force nd axial force or pitching moment of another maneuver. Though the kernels used in this work are valid for linear or weakly non-linear problems, and the predictions are not alway perfect, the ROM can indicate problems in S\&C at greatly reduced amount of time. 


\section{Acknowledgment}

The authors would like to thank the Air Force Office of Scientific Research, AFOSR, for their generous support throughout this project. The financial support of the Modeling and Simulations Center (M\&SRC) of the US Air Force Academy and the financial support of the National Research Council (NRC) is greatly acknowledged. The Arctic Region Supercomputing Center is acknowledged for providing access to high performance computing facilities. The authors want to thank Dr. Walter Silva of NASA-LARc for advice with Volterra functions and Andreas Schütte of DLR for help with X-31 geometry. The first author want to thank Lasse Tyssel for his help with mesh generator TRITET.

\section{References}

${ }^{1}$ Chambers, J. R. and Hall, R. M., "Historical Review of Uncommanded Lateral-Directional Motions at Transonic Conditions," Journal of Aircraft, Vol. 41, No. 3, May-June 2004, pp. 436-447.

${ }^{2}$ Hall, R. M., Woodson, S. H., and Chambers, J. R., "Accomplishments of the Abrupt-Wing-Stall Program," Journal of Aircraft, Vol. 42, No. 3, May-June 2005, pp. 653-660.

${ }^{3}$ Bowers, A. H., Pahle, J. W., Wilson, R. J., Flick, B. C., and Rood, R. L., "An Overview of the NASA F- 18 High Alpha Research Vehicle," NASA TM-4772, Oct. 1996.

${ }^{4}$ Wang, K. C. and Iliff, K. W., "Retrospective and Recent Examples of Aircraft Parameter Identification at NASA Dryden Flight Research Center," Journal of Aircraft, Vol. 41, No. 4, July-August 2004, pp. 752-764.

${ }^{5}$ Moses, R. W., "Fin buffeting features of an early F-22 model," AIAA Paper 2000-1695, April 2000.

${ }^{6}$ Potoczsky, A. S. and Moses, R. W., "An analysis Method to Predict Tail Buffet Loads of Fighter Aircraft," AIAA Paper 2005-2291, April 2005.

${ }^{7}$ Murman, M. M., Chaderjian, N. M., and Pandya, S. A., "Automation of a Navier-Stokes S\&C database generation for the Harrier in ground effect," AIAA Paper 2002-259, 2002.

${ }^{8}$ Chaderjian, N. M., Ahmad, J., Pandya, S., and Murman, S., "Progress Toward Generation of a Navier-Stokes Database for a Harrier in Ground Effect," AIAA Paper 2002-5966, 2002.

${ }^{9}$ Rogers, S. E., Aftomis, M. J., Pandya, S. A., Chaderjian, N. M., Tejnil, E. T., and Ahmad, J. U., "Automated CFD Parameter Studies on Distributed Parallel Computers," AIAA Paper 2003-4229, June 2003.

${ }^{10}$ Görtz, S., McDaniel, D., and Morton, S., "Towards an Efficient Aircraft Stability and Control Analysis Capability Using High-Fidelity CFD," AIAA-2007-1053, 45th AIAA Aerospace Sciences Meeting and Exhibit, Reno, Nevada, Jan. 8-11, 2007.

${ }^{11}$ Matthews, L. L. and Schwartz, M. S., "odeling and Simulations of a Dynamic Maneuvering F-16," AIAA Student Conference, May, 2008.

${ }^{12}$ Jeans, T., McDaniel, D., Cummings, R., and Bergeron, K., "Lower-Order Aerodynamic Loads Modeling of a Maneuvering Generic Fighter Using DDES Simulations," AIAA-2009-0094, 47th AIAA Aerospace Sciences Meeting including The New Horizons Forum and Aerospace Exposition, Orlando, Florida, Jan. 5-8, 2009.

${ }^{13}$ Silva, W. A., "Identification of Nonlinear Aeroelastic Systems based of the Volterra Theory: Progress and Opportunities," Nonlinear Dynamics, Springer, Vol. 39, No. 9, Sept. 2005.

${ }^{14}$ Kvaternik, R. D. and Silva, W. A., "A Computational Procedure for Identifying Bilinear Representations of Nonlinear Systems Using Volterra Kernels," NASA/TM-2008-215320, June 2008.

${ }^{15}$ Beran, P. S., Lucia, D. J., and Pettit, C. L., "Reduced-order modelling of limit-cycle oscillation for aeroelastic systems," Journal of Fluids and Structures, Vol. 19, Sept. 2004.

${ }^{16}$ Lucia, D. J. and Beran, P. S., "Reduced-Order Model Development Using Proper Orthogonal Decomposition and Volterra Theory," AIAA Journal, Vol. 42, No. 6, June 2005.

${ }^{17}$ Silva, W. A., "Discrete-Time Linear and Nonlinear Aerodynamic Impulse Responses for Efficient CFD analysis," PhD Dissertation, Faculty of the Department of Applied Science, The College of William and Mary in Virginia, VA, Sept. 1997.

${ }^{18}$ Strang, W. Z., Tomaro, R. F., and Grismer, M. J., "The Defining Methods of Cobalt: A Parallel, Implicit, Unstructured Euler/Navier- Stokes Flow Solver," AIAA Paper 99-0786, Jan. 1999.

${ }^{19}$ Tomaro, R. F., Strang, W. Z., and Sankar, L. N., "An implicit algorithm for solving time dependent flows on unstructured grids," AIAA Paper 1997-0333, Jan. 1997.

${ }^{20}$ Grismer, M. J., Strang, W. Z., Tomaro, R. F., and Witzemman, F. C., "Cobalt: A Parallel, Implicit, Unstructured Euler/Navier-Stokes Solver," Adv. Eng. Software, Vol. 29, No. 3-6, June 1998.

${ }^{21}$ Karypis, G., Schloegel, K., and Kumar, V., "Parmetis: Parallel Graph Partitioning and Sparse Matrix Ordering Library, Version 3.1," Technical report, Dept. Computer Science, University of Minnesota, 2003.

${ }^{22}$ Morton, S., McDaniel, D., and Cummings, R., "F-16XL Unsteady Simulations for the CAWAPI Facet of RTO Task Group AVT-113," AIAA-2007-493, 45th AIAA Aerospace Sciences Meeting and Exhibit, Reno, Nevada, Jan. 8-11, 2007.

${ }^{23}$ Dean, J., Morton, S., McDaniel, D., and Görtz, S., "Efficient High Resolution Modeling of Fighter Aircraft with Stores for Stability and Control Clearance," AIAA-2007-1652, U.S. Air Force TandE Days, Destin, Florida, Feb. 13-15, 2007.

${ }^{24}$ Morton, S., McDaniel, D., Dean, J., Clifton, J., and Bodkin, D., "Aircraft Stability and Control Characteristics Determined by System Identification of CFD Simulations," AIAA-2008-6378, AIAA Atmospheric Flight Mechanics Conference and Exhibit, Honolulu, Hawaii, Aug. 18-21, 2008.

${ }^{25}$ Jeans, T., McDaniel, D., Cummings, R., and Mason, W., "Aerodynamic Analysis of a Generic Fighter Using Delayed Detached-Eddy Simulation," accepted for publication in the Journal of Aircraft, 2009. 
${ }^{26}$ Powers, S. A. and Shellenger, H. G., "The X-31 - High performance at low cost," AIAA Paper 1989-2122, AHS and ASEE Aircraft Design, Systems and Operations Conference, Seattle, WA, July 31-Aug 2, 1989, 1989.

${ }^{27}$ Ross, H. and Robinson, M., "X-31: 20 Years of Successful International Cooperation," AIAA 2003-2572, AIAA/ICAS International Air and Space Symposium and Exposition: The Next 100 Years, 14-17 July 2003, Dayton, Ohio, 2003.

${ }^{28}$ Tamrat, B., "A Post-Stall Technology (PST) Fighter Close-In-Combat Results Assessment, And A Look At New CIC Performance Evaluation Metric," AIAA Paper 2004-5173, AIAA Atmospheric Flight Mechanics Conference and Exhibit, Providence, Rhode Island, Aug. 16-19, 2004, 2004.

${ }^{29}$ Canter, D. E. and Groves, A. W., "X-31 post-stall envelope expansion and tactical utility testing," AIAA Paper 19942171, Biennial Flight Test Conference, 7th, Colorado Springs, CO, June 20-23, 1994, Technical Papers (A94-28370 09-01), Washington, DC, American Institute of Aeronautics and Astronautics, 1994, 1994.

${ }^{30}$ Alcorn, C. W., Croom, M. A., and Francis, M. S., "The X-31 experience - Aerodynamic impediments to post-stall agility," AIAA Paper 1995-362, Aerospace Sciences Meeting and Exhibit, 33rd, Reno, NV, Jan 9-12, 1995, 1995.

${ }^{31}$ Grohs, T., Fischer, B., Heinzinger, O., and Brieger, O., "X-31 VECTOR - ESTOL to the Ground Flight Test Results and Lessons Learned," AIAA Paper 2004-5029, AIAA Guidance, Navigation, and Control Conference and Exhibit, 16 - 19 August 2004, Providence, Rhode Island, 2004.

${ }^{32}$ Rohlf, D., Brieger, O., and Grohs, T., "X-31 VECTOR System Identification - Approach and Results," AIAA Paper 2004-4830, AIAA Atmospheric Flight Mechanics Conference and Exhibit, 16 - 19 August 2004, Providence, Rhode Island, 2004.

${ }^{33}$ Young, J., "X-31 VECTOR Program Summary," AIAA Paper 2004-5026,AIAA Guidance, Navigation, and Control Conference and Exhibit, Providence, Rhode Island, Aug. 16-19, 2004, 2004.

${ }^{34}$ Williams, D. L., Nelson, R. C., and Fisher, D., "An investigation of X-31 roll characteristics at high angle-of-attack through subscale model testing," AIAA Paper 1994-806, Aerospace Sciences Meeting and Exhibit, 32nd, Reno, NV, Jan 10-13, 1994, 1994.

${ }^{35}$ Rein, M., Höler, G., Schütte, A., Bergmann, A., and Löser, T., "Ground-based simulation of complex maneuvers of a delta-wing aircraf," AIAA Paper 2006-3149, 25th AIAA Aerodynamic Measurement Technology and Ground Testing Conference, 5 - 8 June 2006, San Francisco, California, 2006.

${ }^{36}$ Schütte, A., Einarsson, G., Raichle, A., Schöning, B., Orlt, M., Neumann, J., Arnold, J., Mönnich, W., and Forkert, T., "Numerical Simulation of Maneuvering Aircraft by Aerodynamic, Flight Mechanics and Structural Mechanics Coupling," AIAA Paper 2007-1070, 45th AIAA Aerospace Sciences Meeting and Exhibit, 8 - 11 January 2007, Reno, Nevada, 2007.

${ }^{37}$ Boelens, O. J., "CFD analysis of the flow around the X-31 aircraft at high angle of attack," submitted to the 27th AIAA Applied Aerodynamics Conference, 22-25 June 2009, San Antonio, TX, USA, 2009.

${ }^{38}$ Tyssel, L., "Hybrid Grid Geeneration for complex 3D Geometries," Proceedings of the 7th International Conference on Numerical Grid Generation in Computational Field Simulation, 337-346, Whistler, British Columbia, Canada, Sept. 2000.

${ }^{39}$ Tyssel, L., "The TRITET Grid Generation System," International Society of Grid Generation (ISGG), Proceedings of the 10th International Conference on Numerical Grid Generation in Computational Field Simulations, Forth, Crete, Greece, Sept. 2000 .

${ }^{40}$ Löser, T., "RTO/AVT-161: Assessment of Stability and Control Prediction Methods for NATO Air and Sea Vehicles Thomas Lser, DNW-NWB, X-31 Steady state and dynamic wind tunnel tests," NATO RTO AVT-113 presentation, May 2008.

${ }^{41}$ Jirásek, A. and Cummings, R. M., "Assessment of sting effect on X-31 aircraft model using CFD," NATO-RTO AVT-161 report, to be published, 2010. 